\title{
Correction to: Self-Directed Video Prompting and Least-to-Most Prompting: Examining Ways of Increasing Vocational Skill Acquisition Among Students with Autism Spectrum Disorder and Intellectual Disability
}

\author{
Gulnoza Yakubova $^{1}$ (D) $\cdot$ Louis Leibowitz $^{2} \cdot$ Briella L. Baer $^{1} \cdot$ Nada Halawani $^{3} \cdot$ Lauren Lestremau $^{2}$
}

Published online: 9 November 2019

(C) Springer Nature Switzerland AG 2019

\section{Correction to: Advances in Neurodevelopmental}

Disorders (2019) 3:246-258

https://doi.org/10.1007/s41252-019-0097-5

\begin{abstract}
A correction should be made to the procedural reliability and interobserver agreement (IOA) sub-section within the Method section of the paper. In the Method section of the paper, the procedures for reliability and IOA were stated, however, the results were not. The following were the results: Procedural reliability per student for each phase, i.e., baseline, intervention, and follow-up, was $100 \%$. Similarly, IOA for each student per phase was $100 \%$.
\end{abstract}

Publisher's Note Springer Nature remains neutral with regard to jurisdictional claims in published maps and institutional affiliations.

The online version of the original article can be found at https://doi.org/ 10.1007/s41252-019-0097-5

Gulnoza Yakubova

gulnoza@umd.edu

1 Department of Counseling, Higher Education, and Special Education, University of Maryland, 3214 Benjamin Building, College Park, MD 20742, USA

2 Ivymount School and Programs, Rockville, MD, USA

3 University of Jeddah, Jeddah, Saudi Arabia 